\title{
Promoting Green Living by The Jockey Club Museum of Climate Change in Hong Kong
}

\author{
Ming Kwan ${ }^{1}$, Anthony Kong ${ }^{2} \&$ Terry Lam ${ }^{3}$ \\ ${ }^{1}$ Faculty of Hospitality and Tourism Management, Macau University of Science and Technology, Avenida Wai \\ Long, Taipa, Macau, China \\ ${ }^{2}$ Department of Communication Design and Digital Media at Hong Kong Design Institute, Hong Kong, China \\ ${ }^{3}$ School of Design, The Hong Kong Polytechnic University, Hung Hom, Hong Kong, China \\ Correspondence: Ming Kwan, Faculty of Hospitality and Tourism Management, Macau University of Science \\ and Technology, Avenida Wai Long, Taipa, Macau. E-mail: mwkwan@must.edu.mo
}

Received: March 1, 2019 Accepted: March 25, 2019 Online Published: May 21, 2019

doi:10.5539/ijms.v11n2p55 URL: https://doi.org/10.5539/ijms.v11n2p55

\begin{abstract}
Using the case study of The Jockey Club Museum of Climate Change in Hong Kong, the purpose is to explore how museum can take part to promote green living.

Design/Methodology/Approach-This paper explores the contributions of The Jockey Club Museum of Climate Change as a means to increase environmental awareness for the society. The objectives of The Jockey Club Museum of Climate Change aimed at showing the importance of community involvement, advocating environmentally friendly education and nurturing visitors' moral obligation to engage in pro-environmental protection behavior. Authors conducted twenty-five in-depth semi-structured interviews with visitors so as to fully understand the influences brought by the museum.

Findings - The Jockey Club Museum of Climate Change was perceived by all of the study visitors as a meaningful, influencing and educative museum, which raised environmental awareness, upheld moral obligation to engage in environmental protection, and induced greater pro-environmental behavior. Based on the results, eight benefits are generated by The Jockey Club Museum of Climate Change to environmental protection for the entire globe.

Practical implications-Based on the insights gained from visitors, eight positive influences are contributed by The Jockey Club Museum of Climate Change for nurturing visitors to adopt a green living in order to combat climate change.

Originality/value-This paper urges for the importance of all communities, all business sectors, all kinds of organizations and governments to engage in environmental protection for sustainable development. The aim of such an episode is to arouse all the communities, business sectors, organizations, museums, educational institutions and countries to promote and adopt green living so as to combat climate change.
\end{abstract}

Keywords: green living, low carbon living, museum, climate change

\section{Introduction}

The impacts of climate change and the efforts to combat climate change touch on every part of our lives. The issue of climate change can only be sufficiently addressed with wide participation from the government, different sectors of the community and individuals including museums.

As global warming begins to alert the awareness of the need for greater environmental conservation, energy efficiency, and better places to live and work becomes more prevalent (William, 2008). Similarly, the demand for green buildings and communities is expected to increase as well, for the reason that people today pay more attention to the healthiness and sustainability of the built environment. Therefore, ethics of conservation becomes the norm which is the necessary staple in any sustainable human endeavor (Maser, Beaton, \& Smith, 1998). Nowadays, people focus on development to become more energy efficient and ecologically friendly. Consequently, sustainability has become a touchstone for many of the business sectors (William, 2008). Nevertheless, it leads to the higher demand on energy thus will create bigger burden on the management of solid 
waste, the pollution of water bodies and air has caused negative environmental effects. Owing to these effects, substantial uncertainty exists regarding the long-term implications of such negative environmental impacts, in particular, those relating to global climate change. This increasingly calls for environmental protection of various governments, business sectors and communities. With the continuous growth of the population along with the convergence of rising energy costs, climate change and other pressing environmental issues, all communities, business sectors, non-profit organizations and governments should take the responsibilities for environmental protection and promotion. The adverse impacts of climate change and the responsibility to tackle climate change affect all facet of our lives. The issue of climate change can only be effectively addressed with determination from the government, the business sectors, organizations, and individuals. In fact, the environmental protection is responsibility of everyone in this planet and not simply that of government. Decisions that impact the environment is caused by various stakeholders in this world.

\section{Background of The Jockey Club Museum of Climate Change}

The Jockey Club Museum of Climate Change was built in 2013 in Hong Kong. It is the first museum providing information about climate change through interactive multimedia exhibitions, eco-tour of the prime ecological sites and green facilities and workshops. It is the ideal venue for the public and education institutions to care and concern more about environmental conservation and sustainability (MOCC, 2019).

\section{Literature Review}

\subsection{Museum}

Museums become one of the key players in climate change action that have unique communicative, affective social qualities and promote intergenerational learning for general public (Cameron et al., 2012). It should develop new objectives that respond to local and global social concern as platform for civic engagements as agents for social change (Abram et al., 2005). It should recognize the climate change is an idea and as a phenomenon is shaped by many different human actors. The modes of interactions in museums with audiences, visitors, and publics allow museums to provide sensorial and affective experience through the agency of objects and immersive environments that facilitate the discussion of climate change (Cameron et al., 2012).

\subsection{Sustainable Development}

Over the years, concerns related to the environment have progressively escalated (Laroche et al., 2001). Sustainable development refers to a series of processes and practices, involving action, and focusing on the improvement of human life (WCED, 1987; Blewitt, 2008; UNSGHLPS, 2012). The analogies between sustainability and sustainable development advance towards an interrelationship understanding of a single system composed of human and environmental activities. Such understanding has a dual purpose: to satisfy human's needs and to support life-sustaining systems (Lambin, 2005; Brinsmead \& Hooker, 2011). Thus, sustainability encompasses systems and sustainable development looks towards human needs and their well-being. Human beings are not independent and isolated; they are part of a complex web of natural phenomena inserted in a single global system, which is regarded as a myriad of relationships and interdependencies (Moldan et al., 2012).

Sustainable development is the key to achieve sustainability, which is considered the final long-term goal (Hove, 2004). Sustainability consists of a goal or ultimate objective defined through scientific criteria, which measures and tracks the results generated by the use of sustainable development strategies. In order to achieve the sustainability of a given global system - to raise the level of sustainability quality - it is necessary to use the sustainable development process (Prugh \& Assadourian, 2003; Sartori et al., 2014; Stiglitz et al., 2009).

Sustainability originally was used to describe development and resource consumption that can meet human's present needs while preserving the ability of the environment in sustaining people at present and in future. It involves considering environmental, economic, and social objectives when developing and implementing public policies and programs. It also involves considering the needs of the present as well as the needs of future generations. In other words, sustainable development rests on the harmony between the needs of stakeholders. Instead of being viewed as a destination, sustainable development is an ongoing process whereby behavior is adjusted in the social and economic development and improvement which emphasizes the qualitative improvement in people's well-being. In other words, the concept suggests the community continues to improve the quality of life of its inhabitants (Brandon, 2011). This long-term planning objective of a social-environmental system in balance calls for cooperative functioning among government, institutions, community groups as well as individuals; and the concept is continuously building up from the bottom up through community initiatives. For a business to operate towards sustainability, it should start with the belief that we are part of a larger system 
in business ecology and extends the willingness to examine the larger socio-economic system and how we impact it at the individual, community and organizational level, and eventually at the planetary level (Laing \& Frost, 2010). Hence, green value propositions will include benefits to the physical environment of buildings and facilities, benefits to the community, and improvements to the global environment (Swarbrooke, 1999). It is beneficial to everyone for all businesses, all industry to make environmental sustainability as a management competency and an aspect of organizational excellence (Ahmad et al., 2013). In fact, creating a green culture requires reinforcing people's positive behavior (Ahmad et al., 2013).

\subsection{Community Participation}

Along with the term community, it is said that public participation is considered the centerpiece of the democratic process (Green \& Haines, 2008) which is very essential in community development. In other words, the development of a community requires the involvement and proactive participation of local community in identifying the strategies they wish to use to improve their quality of life (Green \& Haines, 2008). In modern era, much of the policy depends on the knowledge and commitment of the people in approaching the objective of sustainable development. Since local community usually has much better knowledge about the assets and needs of the community, the development project which supported by the local community is more likely to be successful. In response to this, it is important to accomplish a high standard of education coupled with a willingness to make sacrifices at present in order to allow future generations to have choices in their own futures, equal to what we enjoy at present (Brandon, 2011).

\section{Methodology and Research Methods}

Research on green promotion efforts has traditionally employed various deductive processes, testing a plethora of hypotheses and pre-determined theories. Green promotion researchers have typically approached the problem from a positivist perspective, utilizing quantitative research techniques such as questionnaires as well as surveys, and processing data with the help of statistical data analysis tools. While mostly deductive in nature, like research tools tend to measure a set of predetermined hypotheses, searching for answers to the "what" questions and not allowing for any additional factors to enter the researcher's process of reasoning (Yin, 1994). Visitors in the museums context have been shown to demonstrate a multitude of contributions and it is very likely that their attitudes, behaviors, perceptions and experiences of the green promotion ways are different. In order to gain a degree of emotional depth, which is not possible to achieve simply by calculating and analyzing quantitative data, a qualitative research approach has been chosen as a more appropriate research method. Qualitative research is considered to be "concerned with understanding things rather than with measuring them" (Gordon \& Langmaid, 1988 , p. 2), whereby the "subjectivity and the authenticity of human experience" (Silverman, 2010, p. 138) allows the researcher to gain more insights into the deeper meanings, perceptions, feelings and attitudes of research subjects (Holloway et al., 2010; Veal, 2006).

The setting for the present study was The Jockey Club Museum of Climate Change in Hong Kong with the aim of increasing environmental awareness for the community. The objectives of The Jockey Club Museum of Climate Change are showing the importance of community involvement, advocating environmentally friendly education and nurturing visitors' moral obligation to engage in pro-environmental protection behavior.

The Jockey Club Museum of Climate Change was selected in this study because it was the first climate change museum in Hong Kong. The sample group comprised 13 female and 12 male respondents, the ages between 18-55. The education levels of interviewees were secondary (3), undergraduate (12) and postgraduate (10). Due to limited resources available to the researchers made it impracticable to collect data from the entire research population. It is important that the respondents interviewed represent various age, marital status, number of children and career. In the current investigation interviewing would be discontinued once 'saturation' was reached. At this point, no further insights would be forthcoming from the interviews (Myers, 2013). This approach is consistent with the view that sample size is not the dominant concern, in qualitative research, with greater importance attached to richness and depth of data.

Data collection took place at the exit of the museum in late Oct 2018. The researchers undertook one-to-one semi-structured interviews on one to one basis which around 40-75 minutes, at a nearby restaurant. Researchers gave information about the reason of the study and written consent forms were given before interviewing. Questions were set to collect responses regarding each interviewee's attitude, feelings, perceptions and pro-environmental protection behavior after visiting The Jockey Club Museum of Climate Change, exploring general themes proposed by the environmental behavior and personal moral obligation literature. Further questions and prompts were included to enquire their feelings, perceptions and attitudes after The Jockey Club Museum of Climate Change, in order to identify any specific circumstances which may have contributed to a 
participant's pro-environmental behavior and personal moral obligation to engage environmental protection. The interviews were digitally recorded and summaries were written up. Responses were analyzed using manual coding, scanning the recordings and flagging emergent themes and common views (Veal, 2006). Finally, the results were organized into similar conceptual areas based on prevalent themes.

\section{Findings and Discussion}

The success of environmental protection in Hong Kong hinges on community participation. The museum was opened in 2013 with the aim of increasing environmental awareness for the community. The vision of The Jockey Club Museum of Climate Change strives to become an educational venue, valued contributor to bring better changes in knowledge, attitudes and behavior related to climate change throughout Hong Kong and beyond. The mission to reach out to and inform more people in Hong Kong and all over the world about the current issues of climate change. Through a host of initiatives and projects, to encourage and enable all visitors from local and worldwide to participate in carbon-reducing action and living in green.

Motivating the visitors to adopt green living is the key to success. Small steps and large collection can make a better world for all living creatures. Through sustainability by reducing emission of greenhouse gas, decease the wastage of products, facilitating recycling, etc. All the sincere efforts they showed how such efforts can make an influential impact to the world. It is critical to motivate community to take an active role in responding to environmentally friendly measures. According to Goldblatt (2011), he stated three core green strategies for green protection organization: (1) Innovation: creatively harnessing emerging measures and green modern technology for enhancing energy efficiency and environmentalism; (2) Conservation: cherish every use of natural resources and do the utmost to reduce wastage; and (3) Education: educating and encouraging ethical behavior toward energy and the environment while creating positive experiences. The Jockey Club Museum of Climate Change was opened to educate and promote ethical behavior toward energy and the environment while creating enjoyment and educative experiences through innovative exhibitions.

The results of in-depth interviews revealed inspiring insights from visitors' perspectives regarding the experiences and benefits of The Jockey Club Museum of Climate Change in Hong Kong which was derived the values, attitudes, feelings, intrinsic and extrinsic motivations from visitors through engaging various environmental protection actions to achieve the perceived outcome of sustainability and green globe. Based on the result, The Jockey Club Museum of Climate Change in Hong Kong was perceived by all of the study visitors as an insightful, educational, influential, informative, interactive and important museum. It inspired visitors to uphold positive environmental attitudes and engage in pro-environmental behavior in everyday of their lives. It raised environmental awareness, upheld moral obligation to engage in environmental protection, induced greater pro-environmental behavior. Based on the insights gained from museum visitors, lots of benefits are contributed by The Jockey Club Museum of Climate Change for nurturing moral obligation to engage in environmental protection, inducing determination to adopt green living. Eight positive outcomes which are refocusing on strive for a cleaner, healthier and more sustainable environment.

\subsection{Strive for a Cleaner and Sustainable Society}

Through reduced water, waste disposal and energy costs it is saving money for everyone. By practicing waste prevention, reusing products, recycling, and making environmentally conscious purchases, businesses can cut costs and increase profits. Cost savings includes lower waste disposal costs; lower waste treatment costs; lower energy costs; savings on materials and supplies; a reduction in regulatory compliance costs; lower storage costs; cost recovery through the sale of recyclable materials. Reinforcement of environmental protection measures by actual rewards. This further reinforces community's motivation to play a part in recycling activities. Even the policy and planning work from local, regional, national and international governments is essential for combating climate change, individual participation is equally important. Effective and sustainable reduction of carbon emissions hinges on changing people's attitude and habit to adopt a low-carbon lifestyle. Individuals living in daily life take critical role of actual participating in the daily environmental protection practices. The excerpts below show the environmental awareness has been increased after visiting the museum. "After visiting the museum, I have a calling to live a simple and green life. I will pay more focus on sustainable reduction of carbon emissions and to adopt a low-carbon lifestyle". "Lots of environmental education information to help the people of Hong Kong to better understand the potentially devastating effects of climate change and to suggest innovative solutions". "We appreciate the digital and lovely displays in museum to arouse the environmental awareness among visitors". 


\subsection{Raise Awareness of the Balance of Environment and Development}

In The Jockey Club Museum of Climate Change is to advocate a sustainable world based on societies living in harmony with the world. Raise awareness and understanding of the link between environment and development. The excerpt below shows the awareness of the balance of environment and development. "After visiting The Jockey Club Museum of Climate Change, we concern not only the economic development, but we learnt to reduce, reuse, recycle and refocus green world, can yield important social and economic benefits, as well as minimize environmental risks".

\subsection{Care and Concern about all Inhabitants}

All life on earth is connected to the ocean and land and all inhabitants. Climate change affects the whole global, from the mountains to the oceans. People and nature are suffered by water supplies shortage, and extreme weather conditions increasing in frequency and intensity, forests burning, and coral reefs dying. The museum can spread the knowledge to educate and inspire others. For a business to operate towards sustainability, it should start with the belief that we are part of a larger system — a business ecology — and extends the willingness to examine the larger socio-economic system and how we impact it at the individual, community and organizational level, and eventually at the planetary level (Laing \& Frost, 2010). Motivating community to engage voluntarily in pro-environmental behavior is expected to contribute to environmental sustainability by reducing greenhouse gas emissions, reducing waste products, increasing recycling, and specifically climate change is perhaps the greatest challenge humanity has ever faced. It is very important and influential to educate the communities to engage in environmental protection measures daily to ensure sustainable development for future generations. The excerpt below illustrates the importance of sustainable development. "Those meaningful displays in The Jockey Club Museum of Climate Change in Hong Kong are meaningful. I believe those visitors will be inspired to take part to change the world into a better and greener place for human and all inhabitants!". "I deeply admire The Jockey Club Museum of Climate Change, to do their utmost to educate people about green measures, encourage the community to engage in environmentally friendly measures and arouse the environmentally friendly awareness for next generation".

\subsection{Adopting a Low-Carbon Lifestyle}

Some people pay more attention to their needs for convenience or comfort while they are living. Whereas, there are some people who are willing to change their buying behaviors in a more ecologically favorable and behave in an environmentally friendly fashion in their everyday lives, thus sacrificing convenience, accepting lower levels of performance in eco-friendly products, and even paying extra for the products (Kalafatis et al., 1999; Laroche et al., 2001; Manaktola \& Jauhari, 2007). Community's pro-environmental responsibility needs to be remembered for the enhancement of environmental sustainability of all facet of daily lives. To adopt a low carbon lifestyle together for making our better place to live. The excerpt below illustrates the creative ways of living low-carbon lifestyle. "Making better use of nature sunlight, ventilation, shading and scenery, etc. allow us to live comfortably as well as protecting the natural resources". "Add more fruits, vegetables and grains to your diet. Limit red meat consumption. Buy fresh. Avoid frozen or extensively processed and packaged foods".

\subsection{Reducing, Reusing and Recycling}

Solid waste comprises municipal solid waste (MSW), overall construction waste, and special waste. In 2016, the total quantity of solid waste disposed of at the strategic landfills was 5.61 million tonnes (Environmental Protection Department, 2016). Recycling of used paper, glass, food, plastics, electrical appliances, computers, rechargeable batteries, clothes and fluorescent lamps was engaged. The excerpts below illustrate the benefits of recycling and sharing for the needy.

"After knowing the danger of climate change, I will put used paper, glass, food, plastics, electrical appliances, computers, rechargeable batteries, clothes and fluorescent lamps for the needy. One of the best things about recycling is that it helps lower costs to society to handle rubbish. We should recycle materials and protect the environment to benefit people."

\subsection{Use Electricity Wisely}

Unlike waste, which provides a visual cue of its impact on the environment, energy is much harder to quantify and is often taken for granted and treated as an unavoidable cost (Yu et al., 2012). As buildings account for about $90 \%$ of electricity consumption in Hong Kong, there is great potential to improve energy efficiency and reduce our greenhouse gas emissions by promoting energy efficiency in buildings. The museum was held in the outdoor area, only sunlight is used. No air-con and fan were used. The excerpts below illustrate the example of using electricity wisely in hot weather. "Use fan first when I feel hot as it consumes ten times less electricity then 
air-conditioner. Adjust the air-conditioner temperature to $26^{\circ} \mathrm{C}$ and use a fan for improving ventilation can save electricity then using air-conditioner alone with low temperature". "I will ensure a good indoor ventilation by opening as much windows as possible can lower the indoor temperature which help to reduce the reliability on air-conditioning".

\subsection{Ocean Creatures Protection}

Exhibit boards and booths to educate community to be aware of the protection of the oceans. As plastic is now found everywhere in the ocean, from its surface, to its greatest depths and it is serious affecting marine life. The excerpts below illustrate the significance of protecting all the ocean creatures. "I feel angry that human have treated the ocean as both landfill and bottomless provider. Its creatures are harvested to the point of extinction, and pollution, trash and oil spills are thoughtlessly dumped back. Over $80 \%$ of the earth's creatures live in the oceans. Through the exhibition board display, I learnt that the oceans are the source of all life on earth that they provide 50\% of the oxygen we breathe, regulate our climate and our rainfall. It reminded me to take responsibility to protect our oceans and all the ocean creatures." "We should bear in mind that oceans which provide seafood, transport and recreational opportunities for human. We should use all those resources in responsible manner and minimize the negative impacts to ocean creatures". "Plastics that end up as ocean debris contribute to habitat destruction and entangle and kill tens of thousands of marine animals each year. Certain products contribute to the harming of fragile coral reefs and marine populations". "I will make safe, sustainable seafood choices for every meal. As you know, global fish populations are rapidly being depleted due to demand, loss of habitat and unsustainable fishing practices. When shopping or dining out, I will select the seafood that is both healthful and sustainable instead of buying overexploited species". "I bring my reusable water bottle, store food in non-disposable containers, bring my own reusable bag when shopping, and recycle whenever possible so as to reduce plastics waste".

\subsection{Use Eco-Friendly Products}

In fact, the consumption of disposable plastics in everyday is causing major problems globally. All companies and households can pay effort to decrease plastic use and stop disposable consumption. At least bring own shopping bags and use our own refillable cups and bottles, it is the little changes that count. In addition, we need to buy the eco-friendly products and refuse to purchase ozone depleting chemicals. The excerpts below illustrate the example of using eco-friendly products. "I purchase air-conditioners that without containing HCFCs or CFCs as refrigerants; check my air-conditioners and fridge appliances to reduce refrigerant leaks". "I trust the most effective way to protect the ozone layer is not to buy those products that have ozone depleting elements".

\section{Conclusions and Recommendations}

This study aimed to investigate how to promote green living by The Jockey Club Museum of Climate Change in Hong Kong. The efforts to combat climate change touch on every part of our lives and should be the responsibilities of all communities, all business sectors, all organizations and governments. It is important for us to combat climate change, because it will help to safeguard our future. The issue of climate change can only be sufficiently addressed with wide participation from the governments, different sectors of the community, museums, organizations and individuals. The researchers were delighted to learn that The Jockey Club Museum of Climate Change in Hong Kong was perceived by all of the study visitors as influential, informative, and interactive, which raised environmental awareness and promote green living. The results of this study appear to suggest that all the communities, business sectors, organizations and governments should uphold moral obligation to engage in environmental protection and inducing greater pro-environmental behavior for sustainable development. To achieve this, the community must contribute by implementing environmentally friendly measures sincerely and seriously such as refocusing on green education, reducing, reusing and recycling, reinforcing of pro-environmental behavior, respecting ocean creatures protection, refusing to buy ozone depleting chemicals products, responding for sustainable development, rekindling on low-carbon lifestyle and reducing electricity use.

\subsection{Managerial Implications}

The findings of this study have significant implications for environmental protection organizations and museums. Based on the results of this research, the following are suggestions to promote green living for general public. Recommendations to The Jockey Club Museum of Climate Change

- Launch different kinds of meaningful green promotion talks and theme to attract more local and overseas visitors.

- Promote by variety of traditional and social media promotion channels. 


\section{Recommendations to Hong Kong SAR Government}

- Government must review and plan the recycling industry. Shipping out our waste to Mainland China is not a good way for long term perspective.

- Subsidy the recycling industry to develop a greater capacity for processing waste recyclables into usable products.

- Support and subsidy manufacturing capacity for recycled products.

- Government should fully support the recycling industry by subsidizing recycling operations and education on resource recovery and sustainable consumption.

- The Government encourage the public to support local green industry through green procurement.

- To facilitate green business and technology transfer between countries.

- Increase investments to support the business development of clean energy, air quality, transportation

- To direct investment towards ecological infrastructure and renewable energy.

\section{Limitations}

Like all research, this study has a number of limitations which the authors attribute to the relative weakness of interviews to present valid, reliable and trustworthy empirical evidence. Since this study has adopted a qualitative approach, sample size is not a significant issue, despite the small sampling size of interviewees. The focus has been on generating insights on the benefits of The Jockey Club Museum of Climate Change in Hong Kong. The research findings should not to be generalized to the population at large since this was never the intention of the researcher. As this study has employed in-depth interviews as the main mode of data collection, the efficiency and effectiveness of this study will depend to some degree on the researcher's ability to assist participants to derive their thoughts, feelings and experiences in their perception of the benefits after visiting The Jockey Club Museum of Climate Change in Hong Kong. The findings are based on the interviewee's views about how the museum promoted green living. Consequently, it is recognized that the results of this study present a snapshot of thoughts and feelings amongst a specific group of visitors at The Jockey Club Museum of Climate Change in Hong Kong at that specific time. Although the authors make no claims for the generalization of the results, this study has focused on the benefits generated by The Jockey Club Museum of Climate Change in Hong Kong. The findings are useful for all the environmental concerned parties to raise environmental awareness and promote green living for visitors to combat climate change. Hoping all the people in this planet are determinate to combat the climate change by living green in everyday of their lives.

\section{References}

Abram, R. J., DiCosimo, J., Baumann, S. H., Gallant, M., Koster, E. H., Kydd, G., \& Worts, D. (2005). Looking reality in the eye: Museums and social responsibility. University of Calgary Press.

Ahmad, N. L., Rashid, W. E. W., Razak, N. A., Yusof, A. N. M., \& Shah, N. S. M. (2013). Green Event Management and Initiatives for Sustainable Business Growth. International Journal of Trade, Economics and Finance, 4(5), 331. https://doi.org/10.7763/IJTEF.2013.V4.311

Berridge, G. (2007). Events design and experience (Events Management Series, 1st ed.). Elsevier. https://doi.org/10.4324/9780080468112

Blewitt, J. (2012). Understanding sustainable development. Routledge. https://doi.org/10.4324/9781849773645

Brandon, P. S., \& Lombardi, P. (2011). Evaluating sustainable development in the built environment. Chichester, West Sussex; Ames, Iowa: Wiley-Blackwell.

Brinsmead, T. S., \& Hooker, C. (2011). Complex systems dynamics and sustainability: conception, method and policy. In C. Hooker (Ed.), Handbook of the philosophy of science (pp. 809-838). Amsterdam: North-Holland/ Elsevier. https://doi.org/10.1016/B978-0-444-52076-0.50026-2

Cameron, F., Hodge, B., \& Salazar, J. (2013). Representing climate change in museum space and places. Wiley Interdisciplinary Reviews: Climate Change, 4(1), 9-21. https://doi.org/10.1002/wcc.200

Eckerstein, A. (2002). Evaluation of event marketing. International Management Master Thesis, 25, Goteborg University.

Environment Bureau. (2015). Energy Saving Plan for Hong Kong's Built Environment 2015-2025+. Retrieved from https://www.enb.gov.hk/sites/default/files/pdf/EnergySavingPlanEn.pdf 
Environmental Protection Department. (2017). Monitoring of Solid Waste in Hong Kong Waste Statistics for 2016. Retrieved from https://www.wastereduction.gov.hk/sites/default/files/msw2016.pdf

Friends of the Earth. (Aug 2018). Retrieved from https://www.foei.org/about-foei/mission-and-vision

Goldblatt, S (2011). The Complete Guide to Greener Meetings and Events. Hoboken, New Jersey: John Wiley \& Sons, Inc.

Gordon, W., \& Langmaid, R. (1998). Qualitative Market Research: A Practitioner's and Buyer's Guide. Gower, Aldershot.

Green, G. H., \& Haines, A. (2008). Asset building \& community development. Los Angeles: Sage Publications

Holloway, I., Brown, L., \& Shipway, R. (2007). Meaning not measurement: using ethnography to bring a deeper understanding to the participant experience of festivals and events. International Journal of Event and Festival Management, 1(1), 74-85. https://doi.org/10.1108/17852951011029315

Hove, H. (2004). Critiquing sustainable development: a meaningful way of mediating the development impasse? Undercurrent, 1(1).

Kalafatis, S. P., Pollard, M. R., East, R. R., \& Tsogas, M. H. (1999). Green marketing and Ajzen's theory of planned behaviour: a cross-market examination. Journal of Consumer Marketing, 16(5), 441-460. https://doi.org/10.1108/07363769910289550

Kollmuss, A., \& Agyeman, J. (2002). Mind the gap: Why do people act environmentally and what are the barriers to pro-environmental behavior? Environmental Education Research, 8(3), 239-260. https://doi.org/10.1080/13504620220145401

Laing, J., \& Frost, W. (2010). How green was my festival: Exploring challenges and opportunities associated with staging green events. International Journal of Hospitality Management, 29(2), 261-267. https://doi.org/10.1016/j.ijhm.2009.10.009

Lambin, E. F. (2005). Conditions for sustainability of human-environment systems: information, motivation, and capacity. Global Environmental Change, 15(3), 177-180. https://doi.org/10.1016/j.gloenvcha.2005.06.002

Laroche, M., Bergeron, J., \& Barbaro-Forleo, G. (2001). Targeting consumers who are willing to pay more for environmentally friendly products. Journal of Consumer Marketing, 18(6), 503-520. https://doi.org/10.1108/EUM0000000006155

Manaktola, K., \& Jauhari, V. (2007). Exploring consumer attitude and behavior towards green practices in the lodging industry in India. International Journal of Contemporary Hospitality Management, 19(5), 364-377. https://doi.org/10.1108/09596110710757534

Maser, C. R., \& Beaton, S. K. (1998). Setting the Stage for Sustainability. A Citizen's Handbook. Lewis Press.

MOCC. (2019). Museum of Climate Change. Retrieved from http://www.mocc.cuhk.edu.hk/en-gb/

Moldan, B. et al. (2012). How to understand and measure environmental sustainability: Indicators and targets. Ecological Indicators, 17, 4-13. https://doi.org/10.1016/j.ecolind.2011.04.033

Myers, M. (2013). Qualitative Research in Business \& Management (2nd ed.). London: Sage Publications

Ocean Park Conservation Foundation Hong Kong. (2018). Retrieved August 28, 2018, from http://www.opcf.org.hk/en/vision-mission

Prughm, T., \& Assadourian, E. (2003). What is sustainability, anyway? World Watch, 16(5), 10.

Silversm, J. R. (2004). Professional Event Coordination. New Jersey: John Wiley \& Sons Inc.

Slaughter, L., \& Home, R. (2004). Motivations of long-term volunteers: human services vs. events. Journal of Hospitality, Tourism and Leisure Science, 2. Retrieved from http://hotel.unlv.edu/research/htl/articles.html

Smith, K., \& Lockstone, L. (2009). Involving and keeping event volunteers: management insights from cultural festivals. In T. Baum, M. Deery, C. Hanlon, L. Lockstone \& K. Smith (Eds.), People and Work in Events and Conventions: A Research Perspective (pp. 154-168). CABI, Wallingford, CT. https://doi.org/10.1079/9781845934767.0154

Stern, P. C. (2000). New environmental theories: Toward a coherent theory of environmentally significant behavior. Journal of Social Issues, 56(3), 407-424. https://doi.org/10.1111/0022-4537.00175

Stiglitz, J. E., Sen, A., \& Fitoussi, J. P. (2009). Report by the Commission on the Measurement of Economic Performance and Social Progress. 
Swarbrooke, J. (1999). Sustainable tourism management. New York: Cabi. https://doi.org/10.1079/9780851993140.0000

The Jockey Club Museum of Climate Change. (2019). Retrieved from http://www.mocc.cuhk.edu.hk/zh-tw/about-us

United Nations Secretary and General's High-level Panel. (2012). Global Sustainability. Resilient People, Resilient Planet: A Future Worth Choosing. New York: United Nations.

Veal, A. J. (1994). Research Methods for Leisure and Tourism: A Practical Guide (3rd ed.). Pearson Education, Harlow.

WCED. (1987). World Commission on Environment and Development. Our Common Future. Oxford: Oxford University Press.

William, H. H. (2008). Changing metropolitan America: planning or a sustainable future. Washington, D.C.: Urban Land Institute

Wilson, J. (2000). Volunteering. Annual Review of Sociology, 26, $215-240$. https://doi.org/10.1146/annurev.soc.26.1.215

Yin, R. K (1994). Case Study Research: Design and Methods (2nd ed.). Thousand Oaks, CA: Sage.

Yu, L., Wang, C., \& Seo, J. (2012). Mega event and destination brand: 2010 Shanghai Expo. International Journal of Event and Festival Management, 3(1), 46-65. https://doi.org/10.1108/17582951211210933

\section{Copyrights}

Copyright for this article is retained by the author, with first publication rights granted to the journal.

This is an open-access article distributed under the terms and conditions of the Creative Commons Attribution license (http://creativecommons.org/licenses/by/4.0/). 